\section{Kidney \\ Blood Pressure Research}

Kidney Blood Press Res 2015;40:258-265

DOI: $10.1159 / 000368501$

Published online: May 14, 2015

(C) 2015 S. Karger AG, Basel

www.karger.com/kbr

$1423-0143 / 15 / 0403-0258 \$ 39.50 / 0$

Accepted: March 03, 2015

This is an Open Access article licensed under the terms of the Creative Commons AttributionNonCommercial 3.0 Unported license (CC BY-NC) (www.karger.com/OA-license), applicable to

the online version of the article only. Distribution permitted for non-commercial purposes only.

\title{
Pegylated Interferon (Alone or With Ribavirin) for Chronic Hepatitis $C$ in Haemodialysis Population
}

\author{
Mario Espinosa ${ }^{a} \quad$ Jesùs Hernàndez ${ }^{b}$ Maria Dolores Arenas ${ }^{c} \quad$ Fernando Carnicer $^{d}$ \\ Carlos Caramelo $^{\text {b }}$ Fabrizio Fabrizi ${ }^{\mathrm{e}}$
}

aDivision of Nephrology, Reina Sofia University Hospital, Cordoba; ${ }^{b}$ Division of Nephrology, Jimenez Diaz-Capio Foundation, School of Medicine, University of Madrid/Queen Sophie Renal Research Institute, Madrid; 'Division of Nephrology, Perpetuo Socorro Hospital; dDivision of Gastroenterology, General Hospital, Alicante, Spain; eDivision of Nephrology, Maggiore Hospital, IRCCS Foundation, Milano, Italy

\section{Key Words}

Chronic kidney disease $•$ Dialysis $•$ Hepatitis $C \cdot$ Pegylated interferon $•$ Ribavirin

\begin{abstract}
Background/Aims: Hepatitis $C$ virus infection remains prevalent among patients undergoing long-term haemodialysis and has a detrimental impact on survival in this population. Antiviral therapy for chronic hepatitis $C$ in haemodialysis patients is still a challenge to clinicians. The aim of the current study is to evaluate the efficacy and safety of therapy with pegylated interferon, alone or combined with ribavirin, for chronic hepatitis $\mathrm{C}$ among patients undergoing long-term hemodialysis. Methods: We conducted a retrospective, multicenter cohort trial with monotherapy (pegylated interferon) $(n=21)$ or combined antiviral therapy (pegylated interferon plus ribavirin) $(n=5)$ for chronic hepatitis $C$ in patients undergoing long-term haemodialysis. Results: Sustained virological response was obtained in eleven (42\%) patients. Seven $(26.9 \%)$ patients interrupted prematurely the antiviral treatment due to serious sideeffects, the most frequent cause of treatment withdrawal being hematological $(n=3)$. HCV RNA load was lower in responder than non-responder patients, $5.44(3.45 ; 6.36)$ vs. $5.86(4.61$; 6.46) $\log _{10}$ copies $/ \mathrm{mL}$, even if the difference was not significant $(P=0.099)$. Blood transfusion requirement was greater in patients on combined antiviral therapy than those on pegylated interferon alone, $100 \%(5 / 5)$ vs. $0 \%(0 / 21), P=0.0001$. No difference in sustained viral response occurred between patients on combined antiviral therapy and those on pegylated interferon monotherapy [40\% (2/5) vs. 42.8\% (9/21), $P=0.90]$. Conclusions: Results from this study showed that pegylated interferon alone or with ribavirin is unsatisfactory in terms of efficacy
\end{abstract}

In memory of C Caramelo (deceased) for his contribution to this article.

Fabrizio Fabrizi, M.D.
Division of Nephrology, Maggiore Hospital, IRCCS Foundation, Pad. Croff, via Commenda 15, 20122 Milano (Italy)

Tel. +392 55034552, Fax +39255034550, E-Mail fabrizi@policlinico.mi.it 


\section{Kidney Blood Pressure Research}

Kidney Blood Press Res 2015;40:258-265

\begin{tabular}{l|l}
\hline DOI: $10.1159 / 000368501$ & (c) 2015 S. Karger AG, Basel
\end{tabular}

Published online: May 14, 2015

www.karger.com $/ \mathrm{kbr}$

and safety. Prospective trials based on interferon-free regimens (i.e., sofosbuvir plus ribavirin or sofosbuvir plus daclatasvir) are under way in patients with hepatitis $C$ receiving long-term hemodialysis.

Copyright $(2015$ S. Karger AG, Basel

\section{Introduction}

Hepatitis $\mathrm{C}$ virus infection is still frequent in patients with chronic kidney disease, the prevalence of HCV infection among dialysis patients varies greatly from $<5 \%$ to $60 \%$ in different areas of the world [1-2]. Due to the implementation of infection-control procedures against HCV within dialysis units and the elimination of HCV from the blood supply, the incidence of $\mathrm{HCV}$ infection has now declined sharply in many dialysis centers [3].

Recent evidence has been accumulated on an association between anti-HCV seropositive status and impaired survival in the chronic dialysis population. The major complications of HCV-related chronic liver disease (cirrhosis and hepatocellular carcinoma) have been implicated in increased mortality in seropositive patients [4-5]. According to a recent metaanalysis of observational studies ( $n=14 ; 145,608$ unique patients), anti-HCV positive serologic status was an independent and significant risk factor for death in patients on maintenance dialysis. The summary estimate for adjusted relative risk (all-cause mortality) was 1.35 with a $95 \%$ confidence intervals (CI) of 1.25; 1.47. Of note, stratified analysis showed that the adjusted relative risk (aRR) for cardiovascular mortality with anti-HCV was 1.26 (95\% CI, $1.10 ; 1.45)[6]$. Studies are in progress to deepen our understanding of the link between HCV and cardiovascular risk among patients on maintenance dialysis [7].

Antiviral therapy against HCV is uncommonly given in patients undergoing maintenance dialysis despite the KDIGO HCV guidelines had recommended that renal transplant candidates with HCV, dialysis dependent or not, be treated for HCV [8]. Monotherapy with conventional or peg-IFN gives sustained virological response in only one-third of patients on maintenance dialysis with HCV; a drop-out rate of 20-40\% has been found [9]. Ribavirin had been contraindicated in dialysis patients with HCV because of life-threatening haemolytic anaemia. Impaired excretion of ribavirin occurs in patients with CKD, as ribavirin is mostly cleared by kidneys [10]. Very little ribavirin is removed via dialysis so there is a propensity for the drug to accumulate, exacerbating haemolysis in the dialysis population already at risk for anaemia [10]. However, some recent studies support the combination of peg-IFN plus very low dose ribavirin to treat HCV positive haemodialysis patients [11-12].

The aim of this study was to evaluate efficacy and safety of therapy with pegylated interferon, alone or with ribavirin, for chronic hepatitis $\mathrm{C}$ in patients receiving long-term haemodialysis.

\section{Patients and Methods}

\section{Study population}

All patients with anti-HCV positive serologic status who underwent maintenance hemodialysis in three hemodialysis units were considered for analysis. Patients were eligible for the treatment if they met the following criteria: (i) age 18 years or older; (ii) serum positive for HCV RNA by PCR; (iii) aminotransferase elevation above the normal values for patients on regular HD (ALT >28 IU/L); (iv) white blood cell count $>2,500 / \mathrm{mm}^{3}$; (v) platelet count $>75,000 / \mathrm{mm}^{3}$. Exclusion criteria included: (i) any cause for chronic liver disease other than hepatitis C; (ii) untreated major depression; (iii) uncontrolled hyper- or hypothyroidism; (iv) serious autoimmune or systemic disease; (v) positive serologic status for HBsAg or anti-HIV antibody; (vi) evidence for hepatocellular carcinoma (HCC) ( $\alpha$-fetoprotein $>100 \mathrm{ng} / \mathrm{mL}$ ).

All patients underwent long-term haemodialysis (3- or 4-hour standard treatment, three times weekly), and signed an informed consent. Most patients were in the active waiting list for renal transplant. The study was approved by the Institutional Review Board (IRB) at the participating institutions. Patient infor- 


\section{Kidney \\ Blood Pressure Research}

Kidney Blood Press Res 2015;40:258-265

\begin{tabular}{l|l}
\hline DOI: 10.1159/000368501 & C 2015 S. Karger AG, Basel
\end{tabular}

Espinosa/Hernàndez/Arenas/Carnicer/Caramelo/Fabrizi: Interferon for Hepatitis C in Dialysis

mation was managed according to applicable Data Protection Regulations.

Treatment schedule and follow-up

This was a retrospective, multi-center, cohort study. Patients received pegylated interferon $\alpha-2 \mathrm{a}(n=13)$ at $135 \mathrm{mcg}$ or pegylated interferon $\alpha-2 b(n=8)$ at $1 \mathrm{mcg} / \mathrm{kg}$ with a goal of 48 weeks of therapy. Follow-up continued for at least 24 weeks after treatment interruption. Pegylated interferon was administered subcutaneously (SQ) once a week after dialysis. Patients $(n=5)$ on combined antiviral therapy (pegylated interferon $\alpha-2 \mathrm{~b}$ plus ribavirin) received initial ribavirin dose of $200 \mathrm{mg}$ /day orally; ribavirin dose was increased to a maximum of $600 \mathrm{mg} /$ day. Treatment-induced anemia was managed with erythropoietin (EPO) and iron.

Laboratory tests, including a complete blood count, hepatic profile, thyroid hormone, iron kinetics, and $\alpha$-fetoprotein were made at baseline. Then, a complete blood count was performed weekly during the first eight weeks, and every four weeks thereafter. Iron kinetics and hepatic profile were evaluated every month. Genotyping of HCV and quantitative HCV viremia (HCV RNA) were determined in all patients before treatment. Quantitative PCR for HCV RNA testing was made after 12, 24 and 48 weeks of therapy, and at 6 months after the end of treatment.

\section{Measurement methods}

Anti-HCV antibody was measured by a third-generation commercial ELISA (Abbott Imx HCV assay; Abbott Diagnostics); HCV genotyping was carried out using a commercially available line probe assay (Bayer Diagnostics). HCV RNA titers were measured by quantitative PCR (Amplicor, Roche Molecular Diagnostics) with a lower limit of detection of $15 \mathrm{IU} / \mathrm{mL}$. HCV viral load was expressed as $\log _{10}$ copies $/ \mathrm{mL}$.

\section{Primary and secondary outcome}

Primary outcome was sustained virological response; it was defined as undetectable hepatitis C RNA by PCR in serum 24 weeks after stopping the therapy. Secondary endpoint was the withdrawal rate related to adverse effects (AE) for patients receiving at least 1 dose of the study medication. SVR and drop-out rates were calculated according to an intention-to-treat (ITT) analysis.

\section{Statistical analysis}

Descriptive analyses were performed and skewed variables were log-transformed. Proportions were compared using Fisher's exact test and means were compared with Student's $t$-test or Wilcoxon rank sum test, where appropriate. All statistical tests were 2-tailed, and results were statistically significant when a $P$ value was less than 0.05. Statistical analysis was performed using JMP ${ }^{\circledR}$ by SAS Institute Inc, 1996.

\section{Results}

The rate of anti-HCV seropositivity was $10 \%$ in our cohort of patients undergoing maintenance dialysis in three units (around $n=300$ patients). The demographic data of the study patients are shown in Table 1 . Thirteen (50\%) patients underwent percutaneous liver biopsy with ultrasound marking. No significant difference with regard to clinical and background parameters between patients on peg-IFN monotherapy and those on combined antiviral regimen was found (Table 2). Sustained virological response was obtained in 11 (42.3\%) of 26 patients; the kinetics of HCV RNA values at baseline and end of follow-up is given in Figure 1. 


\section{Kidney \\ Blood Pressure Research}

Espinosa/Hernàndez/Arenas/Carnicer/Caramelo/Fabrizi: Interferon for Hepatitis C in Dialysis

No difference in SVR rate occurred between patients on pegIFN monotherapy and those on combined antiviral therapy $[9 / 21 \quad(43 \%)$ vs. $2 / 5$ (40\%), NS]. As listed in Table 3, univariate analysis reported no significant difference between responder and non-respond-

Table 2. Baseline characteristics of patients, according to antiviral treatment. Data presented as mean ( + standard deviation) or median (range) where appropriate

\begin{tabular}{lccc}
\hline & Peg-IFN alone (n=21) & Peg-IFN+Ribavirin $(\mathrm{n}=5)$ & $\mathrm{P}$ \\
\hline Age, years & $51.0 \pm 11.2$ & $42.6 \pm 8.2$ & NS \\
Gender, male (\%) & $14(67 \%)$ & $5(100 \%)$ & NS \\
Time on dialysis, mo & $181.8 \pm 109$ & $143 \pm 126$ & NS \\
HCV, genotype 1 & $15 / 17(88 \%)$ & $4 / 4(100 \%)$ & NS \\
HCV RNA (log 10 copies/mL) & $5.57(3.45 ; 6.36)$ & $5.66(4.45 ; 6.47)$ & NS \\
Fibrosis stage (III-IV) & $2 / 9(22 \%)$ & $1 / 4(25 \%)$ & NS \\
\hline
\end{tabular}

Table 3. Baseline characteristics of patients according to the virological response. Data presented as mean ( \pm standard deviation) or median (range) where appropriate

\begin{tabular}{lccc}
\hline & SVR $(\mathrm{n}=11)$ & No response $(\mathrm{n}=15)$ & $\mathrm{P}$ \\
\hline Age, years & $53.7 \pm 10.4$ & $43.5 \pm 9.5$ & 0.01 \\
Gender, male (\%) & $8(73 \%)$ & $11(73 \%)$ & 0.3 \\
Time on dialysis, mo & $175.6 \pm 101$ & $173.2 \pm 121$ & 0.45 \\
HCV, genotype 1 & $7(77 \%)$ & $12(100 \%)$ & 0.52 \\
HCV RNA (log 10 copies/mL) & $5.44(3.45 ; 6.36)$ & $5.86(4.61 ; 6.46)$ & 0.099 \\
Fibrosis stage (III-IV) & $0 / 5$ & $3 / 8(37.5 \%)$ & 0.44 \\
\hline
\end{tabular}

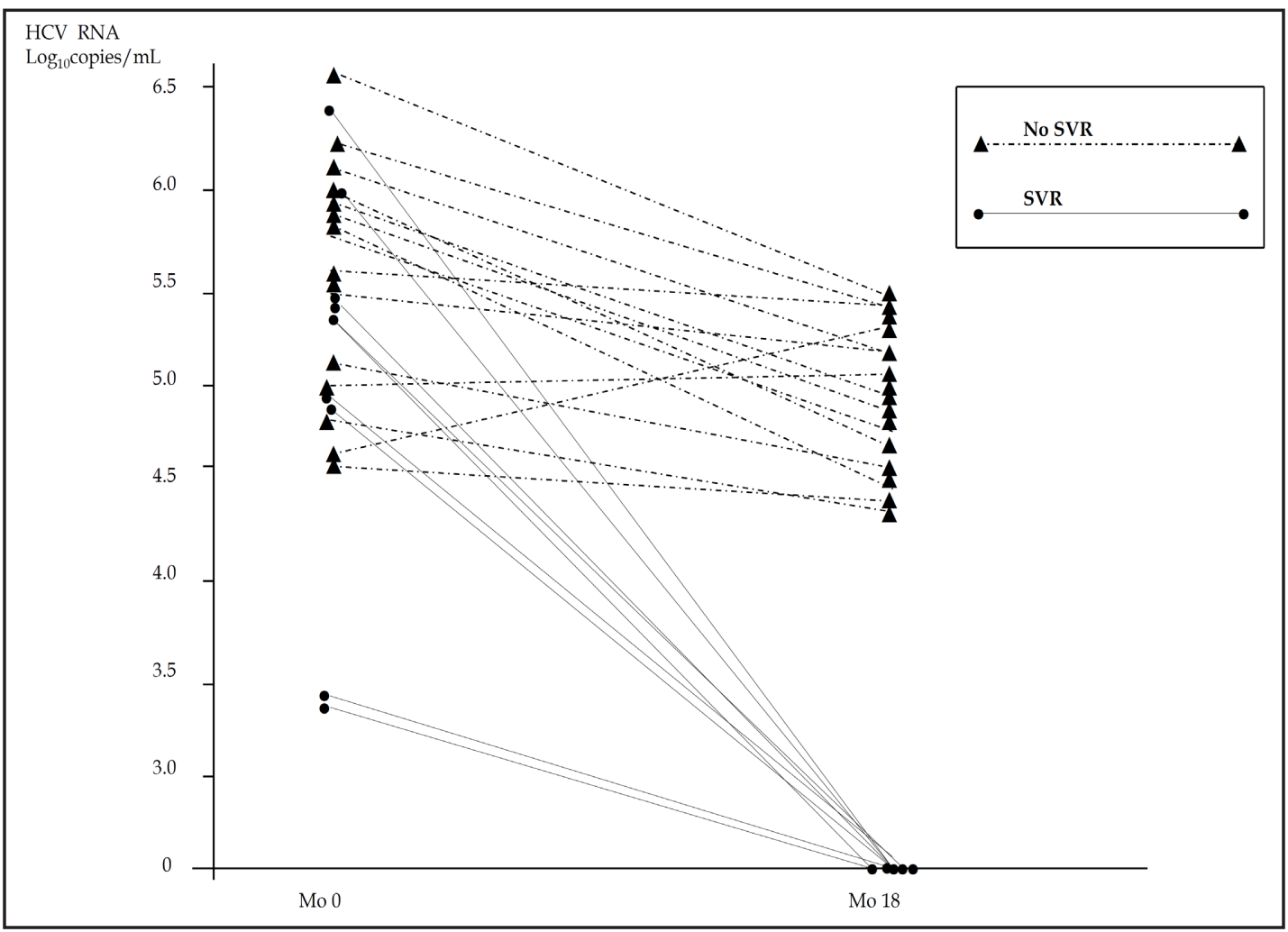

Fig. 1. Mean HCV RNA levels (Baseline/ End Follow-up).

er patients with concern to several covariates. HCV viral load was lower in responders $(P=0.099)$. In the subgroup of patients who underwent liver biopsy $(n=13)$, no difference occurred between viral responders and non-responders on the rate of patients having fi- 


\section{Kidney \\ Blood Pressure Research}

\section{Kidney Blood Press Res 2015;40:258-265}

\begin{tabular}{l|l}
\hline DOI: 10.1159/000368501 & (C) 2015 S. Karger AG, Basel
\end{tabular}

Published online: May 14, 2015

www.karger.com/kbr

brosis stage III or greater [0\% (0/5) vs. $37.5 \%(3 / 8), P=0.5)]$. One patient underwent renal transplant one year after completing antiviral treatment, and disease remission persists 10 years later. Among patients undergoing combined antiviral treatment, the highest ribavirin dose was $600 \mathrm{mg} /$ day that was administered to one patient for two months.

Adverse effects

Treatment discontinuation due to serious side-effects was noted in seven (26.9\%) patients.

Hematological

Anemia was the most frequent side effect and was experienced by all patients on combined antiviral therapy (peg-IFN plus ribavirin), all of them receiving blood transfusions during therapy. Patients on peg-IFN monotherapy or combined antiviral regimen with EPO support at baseline required increased doses during therapy. Blood transfusion requirement was lower among patients on peg-IFN monotherapy than those on combined antiviral therapy $[0 / 21(0 \%)$ vs. $5 / 5(100 \%), P<0.0001]$. Two patients discontinued peg-IFN plus ribavirin therapy due to haemolytic anemia; one drop-out among patients on monotherapy by peg-IFN was related to neutropenia.

\section{Non-hematological}

Many patients had an initial flu-like syndrome, myalgia, and fatigue attributable to peginterferon. The non-hematological reasons for discontinuation of treatment were as follows: peritonitis $(n=1)$, seizures $(n=1)$, hip surgery $(n=1)$, and patient refusal to continue antiviral treatment $(n=1)$. There was no difference regarding drop-out rate between patients on monotherapy with peg-IFN and those on combined antiviral therapy [5/21 (24\%) vs. 2/5 (40\%), NS].

\section{Discussion}

The current study suggests that antiviral therapy of chronic hepatitis $C$ with pegylated IFN alone or with ribavirin was neither effective nor safe. Patients on peg-IFN monotherapy showed SVR rates (around 40\%) slightly greater than those in HCV-infected dialysis patients on monotherapy with conventional IFN (about 30\%). The addition of ribavirin did not lead to an apparent improvement in SVR rates compared to peg-IFN alone. Our study population was a difficult-to-treat group as the majority of patients had HCV genotype 1 which is a predictor of diminished response to interferon in subjects with intact kidney function; also, the limited number of patients we have included hampers definitive conclusions. However, the results of our study are quite different from those found in patients with hepatitis $\mathrm{C}$ and intact kidney function where the SVR rate was less than 15\% in patients on monotherapy with recombinant IFN, and a dramatic improvement in SVR rates was noted with the addition of ribavirin, and later with the substitution of peg-IFN instead of standard IFN $(50-80 \%$ according to HCV genotype) [13].

The withdrawal rate due to side-effects $(26.9 \%)$ was rather high, the most important adverse events being haematological. The addition of ribavirin resulted in drop-out related anemia $(n=2)$ and blood transfusion requirement was larger in patients on combined antiviral therapy (pegIFN plus ribavirin) than those on peg-IFN monotherapy. The dose of EPO was increased in all study patients who had received erythropoietin at baseline. Markedly reduced doses of ribavirin (200 mg daily or $200 \mathrm{mg}$ thrice weekly) could improve the tolerance of combination antiviral therapy for HCV in the dialysis population, as indicated in recent clinical trials [11-12, 14-15], even if large doses of EPO and close monitoring of haemoglobin values are warranted. 


\section{Kidney Blood Pressure Research}

Kidney Blood Press Res 2015;40:258-265

\begin{tabular}{l|l}
\hline DOI: 10.1159/000368501 & (c) 2015 S. Karger AG, Basel
\end{tabular}

Published online: May 14, 2015

www.karger.com/kbr

263

Controversy exists concerning the prescription of ribavirin in the setting of advanced chronic kidney disease. The manufacturer's product information for ribavirin indicates that patients with creatinine clearance less than $50 \mathrm{~mL} / \mathrm{min}$ should not take ribavirin and the drug should be prescribed in combination with interferon only. Ribavirin monotherapy shows no impact on viral response [16]. Patients on long-term dialysis are prone to develop drug-related toxicity, particularly ribavirin-induced anaemia; also, the pharmacokinetic profile of interferons in dialysis population is largely different from that observed in healthy individuals [16]. The KDIGO guidelines have already indicated interferon monotherapy for HD patients [8]. Prior HCV guidelines from the American Association for the Study of Liver Disease (AASLD) had recommended that patients with renal failure should not be treated with ribavirin [17] but the 2009 update indicates that markedly low doses of ribavirin should be given in patients on maintenance dialysis by experienced physicians with careful monitoring of haemoglobin levels [18].

Novel evidence suggests that hepatitis $C$ is rarely treated among patients undergoing long-term haemodialysis [19], although it is desirable to treat HCV before transplantation. IFN is generally avoided after transplantation due to concern of inducing kidney rejection and relapse after kidney transplantation generally does not occur in cases of sustained viral response obtained while the patient is still undergoing maintenance dialysis [20]. It is possible that nephrologists choice not to treat HCV and some patients decline antiviral therapy due to anxiety about the adverse events associated with treatment. The extent of liver damage is frequently underestimated by clinicians as liver enzymes remain normal in most dialysis patients with HCV [21] and physicians are reluctant to perform liver biopsy in these patients due to platelet dysfunction.

The rather low rate of virological response and the high frequency of drop-outs reported in the current study do not support IFN-based regimens for HCV treatment in the dialysis population. For the past 20 years, interferon and then peg-IFN have been the backbone of HCV treatment on which ribavirin and more recently HCV protease inhibitors have been added [22]. A better understanding of the lifecycle of HCV has led recently to the development of several DAAs that have the potential to dramatically increase the efficacy and safety of antiviral treatments of HCV [22-23]. Triple antiviral therapy, i.e, peg-IFN $\alpha$, ribavirin plus protease inhibitors (telaprevir and boceprevir) has been recently considered the standard of care for genotype $1 \mathrm{HCV}$ infection in patients with intact kidney function [22]. No dosage adjustment of telaprevir or boceprevir has been required for patients with renal impairment because they are mostly cleared by the liver. Telaprevir-based triple therapy has been given to 4 patients with HCV genotype 1 on haemodialysis who did not respond to peg-IFN plus low-dose ribavirin. Three patients obtained clearance of HCV RNA from serum before week 12 of treatment and tolerance to treatment was good, except for mild anemia leading to increasing EPO doses [24]. The development of new protease inhibitors (such as simeprevir) [25], nucleoside polymerase inhibitors (such as sofosbuvir) [26] or NS5A polymerase inhibitors (such daclatasvir) [27] promises to open a novel perspective on the treatment of HCV infection but data in patients with kidney impairment are not currently available.

Our study has a few limitations. First, this study was retrospective, which made impossible to randomly allocate subjects in the combined antiviral regimen. No reasons for differential bias in allocation are however expected. This was further confirmed by independence of age, gender and other background parameters to combined antiviral regimen. Second, sample size is small, and this diminished this study's power to detect small effects certain variables may have on the virological response. That said, our study group resulted from the screening of a large number of patients undergoing regular dialysis at three hemodialysis units. Finally, the pharmacokinetics of peg-IFN and ribavirin has not been well established in patients on peritoneal dialysis, thus our results may not be generalizable to patients on peritoneal dialysis. 


\section{Kidney \\ Blood Pressure Research}

Kidney Blood Press Res 2015;40:258-265

\begin{tabular}{l|l}
\hline DOI: $10.1159 / 000368501$ & (c) 2015 S. Karger AG, Basel
\end{tabular}

Published online: May 14, 2015

www.karger.com/kbr

\section{Conclusion}

Our study shows that the SVR rate (about 40\%) with pegylated IFN monotherapy was unsatisfactory and the addition of ribavirin did not lead to improved virological response. PegIFN-based therapy was not well tolerated. For 2014, sofosbuvir has replaced peg-IFN as the backbone of HCV therapy: the treatment of HCV continues to evolve rapidly but little is known about treatment in groups different from the general population including patients on maintenance dialysis. Affordability of these innovative regimens will also be an issue, particularly in resource-constrained countries.

\section{Abbreviations}

CKD, chronic kidney disease; DAAs, direct-acting antiviral agents; EPO, erythropoietin; HCV, hepatitis C virus; HD, haemodialysis; IFN, interferon; peg-IFN, pegylated interferon; SD, standard deviation; SVR, sustained virological response.

\section{Disclosure Statement}

The authors of this manuscript state that they do not have any conflict of interests and nothing to disclose.

\section{References}

1 Fissell R, Bragg-Gresham J, Woods J, Jadoul M, Gillespie B, Hedderwick S, Rayner H, Greenwood R, Akiba T, Young E: Patterns of hepatitis C prevalence and seroconversion in hemodialysis units from three continents: the DOPPS. Kidney Int 2004;65:2335-2342.

2 Finelli L, Miller JT, Tokars JI, Alter MJ, Arduino MJ: National surveillance of dialysis-associated diseases in the United States, 2002. Semin Dial 2005;18:52-61.

3 Espinosa M, Martin-Malo A, Ojeda R, Santamaria R, Soriano S, Aguera M, Aljama P: Marked reduction in the prevalence of hepatitis $\mathrm{C}$ virus infection in hemodialysis patients; causes and consequences. Am J Kidney Dis 2004;43:685-689.

4 Espinosa M, Martin-Malo A, Alvarez de Lara M, Aljama P: Risk of death and liver cirrhosis in anti-HCV positive long-term haemodialysis patients. Nephrol Dial Transplant 2001;16:1669-1674.

5 Kalantar-Zadeh K, McAllister C, Miller L: Clinical characteristics and mortality in hepatitis C-positive haemodialysis patients: a population based study. Nephrol Dial Transplant 2005;20:1662-1669.

6 Fabrizi F, Dixit V, Messa P: Impact of hepatitis C on survival in dialysis patients: a link with cardiovascular mortality ? J Viral Hepat 2012;19:601-607.

$7 \quad$ Fabrizi F, Messa P, Martin P: Recent advances on hepatitis C virus in dialysis population. Kidney Blood Press Res 2014;39:260-271.

8 Kidney Disease: Improving Global Outcomes (KDIGO): KDIGO clinical practice guidelines for the prevention, diagnosis, evaluation, and treatment of hepatitis $\mathrm{C}$ in chronic kidney disease. Kidney Int Suppl 2008;109:S1-99.

9 Gordon C, Uhlig K, Lau J, Schmid C, Levey A, Wong J: Interferon treatment in hemodialysis patients with chronic hepatitis $C$ virus infection: a systematic review of the literature and meta-analysis of treatment efficacy and harms. Am J Kidney Dis 2008;51:263-277.

10 Gupta S, Kantesaria B, Glue P: Pharmacokinetics, safety, and tolerability of ribavirin in hemodialysisdependent patients. Eur J Clin Pharmacol 2012;68:415-418. 


\section{Kidney \\ Blood Pressure Research}

11 Liu C, Liu C, Huang C, Lin J, Dai C, Liang C, Huang J, Hung P, Tsai H, Tsai M, Lee C, Chen S, Yang S, Su T, Yang H, Chen P, Chen D, Chuang W, Yu M, Kao J: Peginterferon alfa-2a with or without low-dose ribavirin for treatment-naive patients with hepatitis $\mathrm{C}$ virus genotype 2 receiving haemodialysis: a randomised trial. Gut 2015;64:303-311.

12 Liu C, Huang C, Liu C, Dai C, Liang C, Huang J, Hung P, Tsai H, Tsai M, Chen S, Lin J, Yang S, Su T, Yang C, Chen P, Chen D, Chuang W, Yu M, Kao J: Pegylated interferon -alpha 2a with or without low-dose ribavirin for treatment-naive patients with hepatitis $C$ virus genotype 1 receiving hemodialysis. Ann Intern Med 2013;159:729-738.

13 Fabrizi F, Dixit V, Martin P, Messa P: Antiviral therapy (pegylated interferon and ribavirin) of hepatitis C in dialysis patients: meta-analysis of clinical studies. J Viral Hepat 2014;21:681-689.

14 Tseng P, Chen T, Chien Y, Hung C, Yen Y, Chang K, Tsai M, Lin M, Lee C, Shen C, Hu T: Efficacy and safety of pegylated interferon $\alpha-2 b$ and ribavirin combination therapy versus pegylated interferon monotherapy in hemodialysis patients: a comparison of 2 sequentially treated cohorts. Am J Kidney Dis 2013;62:789-795.

15 Rendina M, Schena A, Castellaneta N, Losito F, Amoruso A, Stallone G, Schena F, Di Leo A, Francavilla A: The treatment of chronic hepatitis $C$ with peginterferon alfa-2a $(40 \mathrm{kDa})$ plus ribavirin in haemodialysis patients awaiting renal transplant. J Hepatol 2007;46:768-774.

16 Berenguer M: Treatment of chronic hepatitis C in hemodialysis patients. Hepatology 2009;48:1690-1699.

17 Strader D, Wright T, Thomas D, Seeff L, American Association for the Study of Liver Diseases: Diagnosis, management, and treatment of hepatitis C. Hepatology 2004;39:1147-1171.

18 Ghany M, Strader D, Thomas D, Seeff L: Diagnosis, management, and treatment of hepatitis C: an update. Hepatology 2009;49:1335-1374.

19 Goodkin D, Bieber G, Gillespie B, Robinson M, Jadoul M: Hepatitis C infection is very rarely treated among haemodialysis patients. Am J Nephrol 2013;38:405-412.

20 Weclawiak H, Kamar N, Ould-Mohamed A, Cardeau-Desangles I, Izopet J, Rostaing L: Treatment of chronic hepatitis C virus infection in dialysis patients: an update. Hepat Res Treat 2010;2010:267412.

21 Guh J, Lai Y, Yang C, Chen S, Chuang W, Hsu T, Chen H, Chang W, Tsai J: Impact of decreased serum transaminase levels on the evaluation of viral hepatitis in haemodialysis patients. Nephron 1995;69:459465.

22 Aghemo A, De Francesco R: New horizons in hepatitis C antiviral therapy with direct-acting antivirals. Hepatology 2013;58:428-438.

23 American Association for the Study of Liver Diseases (AASLD), Infectious Diseases Society of America (IDSA) and International Antiviral Society (IAS). Recommendations for testing, managing, and treating hepatitis C (http://www.hcvguidelines.org/).

24 Dumortier J, Guillaud O, Gagnieu M, Janbon B, Juillard L, Morelon E, Leroy V: Antiviral triple therapy with telaprevir in haemodialysed HCV patients: is it feasible ? J Clin Virol 2013;56:146-149.

25 Shiffman M: Hepatitis C virus therapy in the direct acting antiviral era. Curr Opin Gastroenterol 2014;30:217-222.

26 Gane E, Stedman C, Hyland R, Ding X, Svarovskaia E, Symonds W, Hindes R, Berrey M: Nucleotide polymerase inhibitor sofosbuvir plus ribavirin for hepatitis C. N Engl J Med 2013;368:34-44.

27 Pol S, Ghalib R, Rustgi V, Martorell C, Everson G, Tatum H, Hezode C, Lim K, Bronowicki J, Abrams G, Brau N, Morris D, Thuluvath P, Reindollar R, Yin P, Diva U, Hindes R, McPhee F, Hernandez D, Wind-Rotolo M, Hughes E, Schnittman S: Daclatasvir for previously untreated chronic hepatitis C genotype-1 infection: a randomised, parallel-group, double-blind, placebo-controlled, dose-finding, phase 2a trial. Lancet Infect Dis 2012;12:671-677. 